\title{
Xanthogranulomatous inflammation of terminal ileum: report of a case with small bowel involvement
}

\author{
KC Wong *, Wilson MS Tsui, SJ Chang
}

\begin{abstract}
A B S T R A C T
Xanthogranulomatous inflammation is a rare pathological condition most frequently detected in the kidney and gallbladder. Reported herein is a case of xanthogranulomatous inflammation in a 51-year-old male presenting as a mass-forming lesion in the terminal ileum with mucosal ulceration. Diagnostic laparoscopy followed by ileocecectomy was performed due to intra-operative suspicion of carcinoma of appendix. This is a report of the condition involving the terminal ileum with mucosal ulceration and full-thickness involvement of bowel wall which are uncommon features of
\end{abstract}

xanthogranulomatous inflammation in previously reported lower gastro-intestinal tract lesions.

\section{Hong Kong Med J 2015;21:69-72 \\ DOI: $10.12809 / \mathrm{hkmj} 134103$}

${ }^{1}$ KC Wong *, MCSHK, MRCSEd

2 WMS Tsui, FIAC, FRCPath

${ }^{1}$ SJ Chang, FRCS, FRCSEd

Department of Surgery

2 Department of Pathology

Caritas Medical Centre, Shamshuipo, Hong Kong

* Corresponding author: kamkam44@gmail.com

\section{Introduction}

Xanthogranulomatous inflammation (XGI) is a rare but well-defined disease, first reported by Oberling in $1935 .^{1}$ The disease process was most frequently reported in the kidney and gallbladder. Rare occurrence in the gastro-intestinal tract was illustrated in only one recently reported case in the terminal ileum, ${ }^{2}$ four reported cases in the colon, ${ }^{3-6}$ eight cases in a series of interval appendicectomy specimens, ${ }^{7}$ and eight cases with gastric involvement. $^{8-13}$ Of the four cases with colonic involvement, two involved the sigmoid colon, ${ }^{3,4}$ one involved the caecum, ${ }^{5}$ and one involved the ascending colon. ${ }^{6}$ Most of these colonic lesions presented with a mass-forming lesion with predominant submucosal involvement, while primary mucosal involvement was only reported in the last case involving the ascending colon. We, herein, report the second case of XGI in the terminal ileum with mucosal ulceration and full-thickness involvement of the bowel wall, presenting as a painful right-lower-quadrant abdominal mass.

\section{Case report}

A 51-year-old Chinese male presented to the Emergency Department on 2 December 2012. He was a chronic smoker and alcoholic. He complained of right-sided abdominal pain for the past 2 weeks. The pain was not associated with nausea, vomiting, constipation, or diarrhoea. There was no anorexia or weight loss. There was no history of melaena. His medical history included diabetes, hypertension, and gout. There was no history of tuberculosis.

He was admitted to a hospital in Mainland China 10 days before the index admission for the same problem. While in that hospital, he had raised white cell count of $16.2 \times 10^{9} / \mathrm{L}$, and an ultrasound of abdomen revealed a gallstone and a renal stone. There was no hydronephrosis. A course of antibiotics was given, but the symptoms persisted. The patient returned from Mainland China on 2 December 2012, and attended our Emergency Department for further management.

On admission, the physical examination of the respiratory, cardiovascular, and central nervous systems was unremarkable. Abdominal examination revealed tenderness in the right lower quadrant. Per rectal examination revealed no blood, melaena, or mass. Abdominal X-ray showed no specific abnormalities.

His blood tests revealed mildly elevated white cell count of $10.6 \times 10^{9} / \mathrm{L}$ (reference range [RR], 3.7-9.2 $\left.\times 10^{9} / \mathrm{L}\right)$, haemoglobin level of $137 \mathrm{~g} / \mathrm{L}$ (RR, 134-171 g/L), normal amylase level of $57 \mathrm{U} / \mathrm{L}$ (RR, 30-128 U/L), and normal electrolytes and liver enzymes. An urgent ultrasound of the abdomen and pelvis raised suspicion of acute appendicitis, with a tubular, non-peristaltic, non-compressible structure measuring $1.55 \mathrm{~cm}$ in diameter at the appendicular region, with small amount of loculated fluid around the lesion (Fig 1), corresponding with the site of maximum tenderness. The distal end of the lesion was obscured by bowel gas; it could not be ascertained whether it was blind-ended. The same study also revealed the presence of a gallstone and a 


\section{迴腸末端的黄色瘤樣肉芽腫性炎：牽涉小腸的 病例報告 \\ 黃洤璋、崔文山、張世傑 \\ 黄色瘤樣肉芽腫性炎是一種罕見病變, 最常見於腎及膽囊。本文報告 一例 51 歲男性主訴右下腹疼痛, 腹腔鏡顯示炎症累及盲腸、闌尾及迴 腸末端。由於懷疑闌尾癌而進行盲腸、闌尾及迴腸末端切割手術。臨 床病理學觀察確診迴腸末端黄色瘤樣肉芽腫性炎。病灶累及全層腸壁 並不常見於其他文獻報告的下消化道同類病變。}

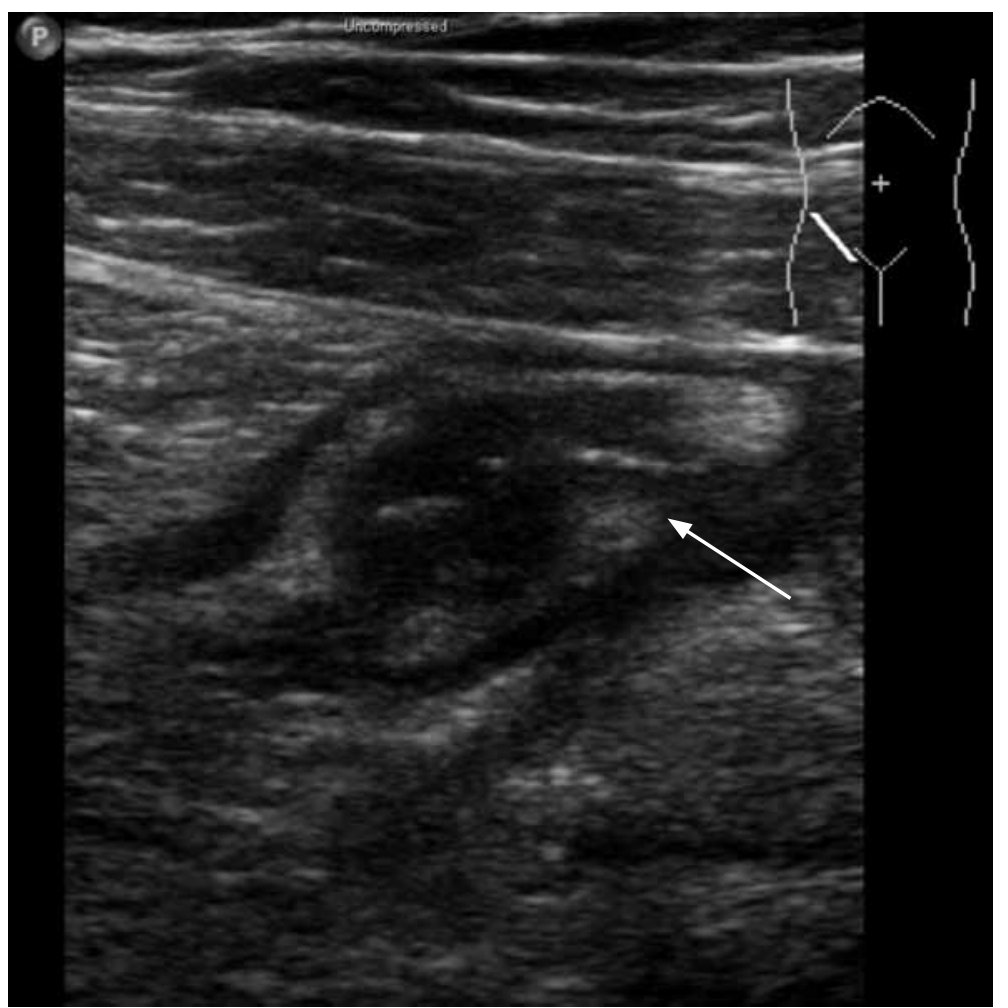

FIG I. An ultrasound image of the right-lower-quadrant mass showing a tubular, non-peristaltic, non-compressible structure in the appendicular region with small amount of loculated free fluid (arrow) around the lesion. The distal end of the lesion is obscured by bowel gas; it could not be ascertained whether it was blindended infiltrative tumour. The mass demonstrated throughand-through invasion into the ileal mesentery, involving several loops of the ileum. Ileocaecal lymph node enlargement was noted. The appendix was not identified. There was no gross cavity or pus. With the suspicion of carcinoma of appendix, limited right hemicolectomy with en-bloc resection of the mass together with $65 \mathrm{~cm}$ of the terminal ileum, caecum, and proximal ascending colon was performed. Primary sub-end to sub-end, side-toside anastomosis was fashioned.

The postoperative course of the patient was complicated by on-and-off fever with elevated white cell count of up to $22.5 \times 10^{9} / \mathrm{L}$. Blood culture taken on postoperative day 2 yielded no bacterial growth. Erythema and serous discharge were noted in the paraumbilical region of the laparotomy and gridiron wounds, which were managed with dressing and packing. Wound swab yielded scanty growth of Escherichia coli. The fever responded to a 10-day course of cefuroxime and metronidazole. He was discharged on postoperative day 10 .

A colonoscopy done 4 months after the operation in April 2013 revealed no abnormalities.

\section{Pathological examination}

Gross examination of the ileocolectomy specimen revealed a $0.5-\mathrm{cm}$ ileal mucosal ulcer, which was $1.5 \mathrm{~cm}$ proximal to the ileocaecal valve. The periappendicular mass was haemorrhagic and covered with exudate, within which was a retrocaecal appendix, measuring $5 \mathrm{~cm}$ in length and $1 \mathrm{~cm}$ in diameter, surrounded by necrotic and yellowish tissue. Cut surface of the appendix was unremarkable. A few lymph nodes were found in the ileocaecal fossa.

Microscopic examination of the appendicular mass showed abscess, haemorrhage, and XGI which consisted predominantly of foamy histiocytes, scattered neutrophils, lymphoplasmacytic cells, a few multinucleated giant cells, and congested capillaries with surrounding fibrosis (Fig 2). The foamy histiocytes were positive for CD68 on immunostaining, confirming their histiocytic origin. No Michaelis-Gutmann bodies were detected. The terminal ileum ulcer revealed similar XGI which extended through the bowel wall to involve the mesentery. The appendicular mucosa showed no neutrophilic infiltrate. A few reactive lymph nodes were noted. There was no evidence of malignancy or granuloma.

\section{Discussion}

Xanthogranulomatous inflammation is a form of chronic inflammatory condition characterised macroscopically by mass-forming golden yellow tumours and microscopically by aggregation of lipid- 


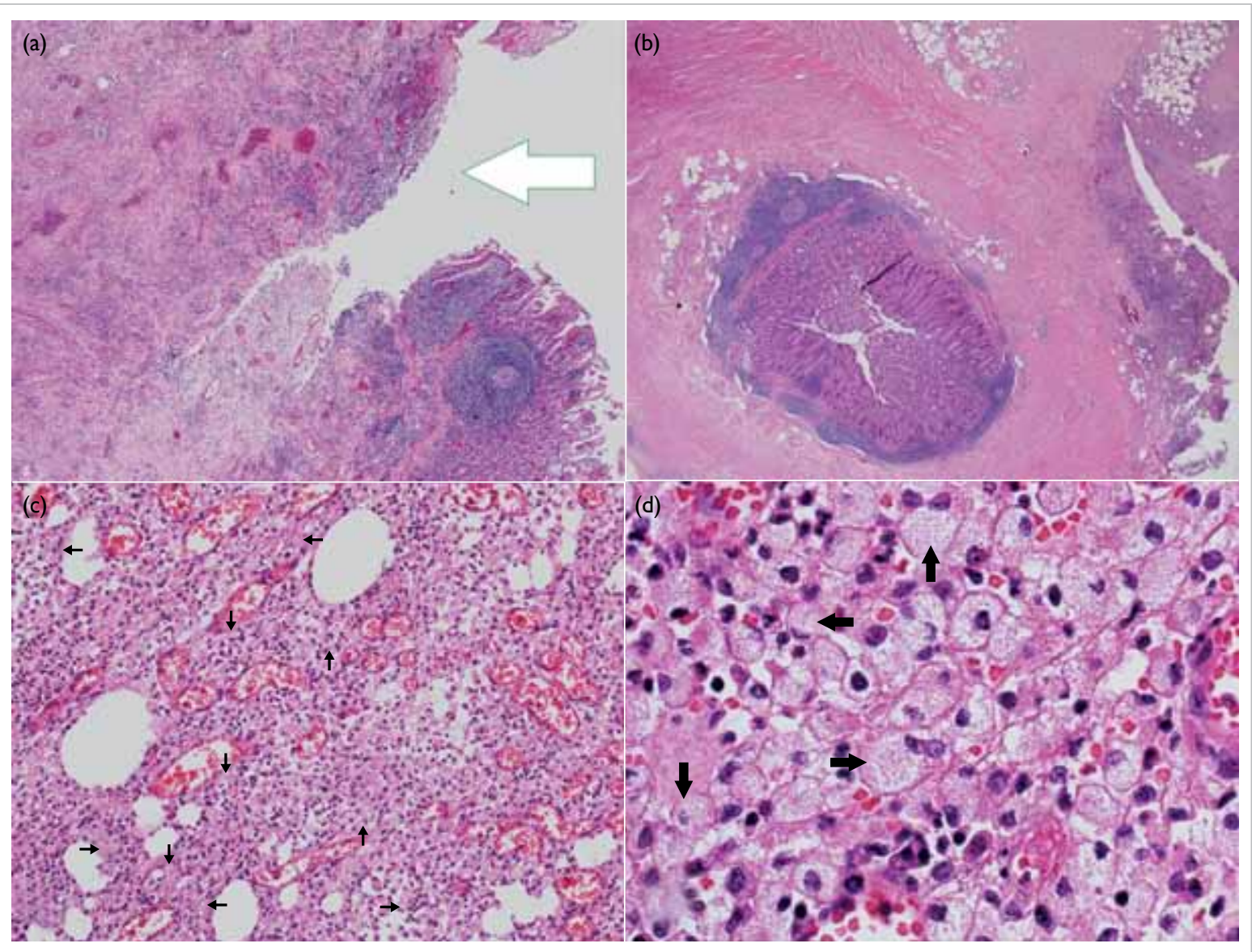

FIG 2. Microscopic examination of the appendicular mass. (a) Terminal ileum featuring ulceration (arrow) and underlying inflammation (H\&E; original magnification, $x$ 10). (b) Appendix buried in the inflammatory mass but showing intact muscle wall and non-inflamed mucosa (H\&E; original magnification, $x$ 10). (c) Xanthogranulomatous inflammation comprising mainly foamy histiocytes (arrows), scattered neutrophils, a few lymphoid cells, and congested capillaries (H\&E; original magnification, $x$ 100). (d) High-power view to reveal the lipid-laden foamy histiocytes (arrows) [H\&E; original magnification, $x$ 400]

laden foamy histiocytes including multinucleated giant cells, with a minor component of chronic and acute inflammatory cells and fibrous reaction. It was first described by Oberling in 1935 in three cases of retroperitoneal xanthogranulomas. ${ }^{1}$ Its occurrence in the endometrium, ovary, fallopian tubes, vagina, testis, epididymis, stomach, bone, skin (as fistulation secondary to inflammation primarily involving another internal organ), ${ }^{14}$ appendix, ${ }^{7,15}$ urinary bladder, thyroid, and adrenal glands has been reported, with the highest prevalence reported in the kidney and gallbladder. A majority of XGI cases present as a mass-like lesion with an extension of fibrosis and inflammation to the surrounding tissues, leading to diagnostic difficulties in differentiating them from infiltrative malignant tumours.

Pathological differential diagnoses bearing similar histological features include malakoplakia, which is characterised by an inflammatory and destructive xanthomatous proliferation with the presence of Michaelis-Gutmann bodies, which are intracytoplasmic laminated concretions usually positive for periodic acid-Schiff, von Kossa, and Prussian blue stains. Macrophages known as von Hansemann cells are more granular and eosinophilic and have less vacuolated cytoplasm than ordinary histocytes. Other differential diagnoses include localised xanthoma deposits without parenchymal destruction or xanthomas with prominent foam cell features.

Although the pathological features of XGI are well described, its exact pathogenesis is not well established.

Various proposed mechanisms include chronic recurrent infection, obstruction, immunological disorders, and defective lipid transport. It is generally believed that the localised proliferation of lipidladen foamy histiocytes in XGI represents chronic suppurative inflammation secondary to interaction between the host and microorganisms. Examples of immunological disorders include disrupted chemotaxis of polymorphs and macrophages, which 
is a specific immune response toward Proteus and Escherichia infections. A recently reported case ${ }^{2}$ involving the terminal ileum proposed a possible mechanism of perforation due to an ingested foreign body. However, none of the above hypotheses were able to fully explain the anatomical distribution of the condition, which is most common in the appendix where neither perforation due to ingested foreign bodies nor chronic suppurative inflammation is most often found. In this reported case, infected laparotomy wound swab yielded $E$ coli, while there were no symptoms to suggest pre-existing chronic suppurative inflammation. There was no evidence of a penetrating foreign body on history or gross examination of the pathological specimen.

Rare occurrence of XGI in the lower gastrointestinal tract is illustrated by only one reported case in the terminal ileum, ${ }^{2}$ four reported cases in the colon with two involving the sigmoid colon, ${ }^{3,4}$ one involving the caecum, ${ }^{5}$ and one involving the ascending colon. ${ }^{6}$ However, a histopathological review of 22 interval appendicectomy specimens by Guo and Greenson ${ }^{7}$ in 2003 reported presence of XGI in eight cases (36.4\%) of interval appendicectomy versus none in the 44 matched patients receiving acute appendicectomy, suggesting XGI may be under-reported as a delayed consequence of acute inflammation and that these histological changes are secondary to the time interval of inflammation rather than intrinsic factors specific to the patient or disease.

Due to endoscopic, radiological, and the intraoperative macroscopic resemblance to infiltrative malignant neoplasms, these lesions warrant excision with a wide margin, similar to treatment of locally advanced malignancies.

However, there has been inadequate evidence to suggest association between XGI and gastrointestinal malignancies. Of the eight cases of XGI of the stomach reported in the literature, ${ }^{8-13}$ coexistence of XGI with gastric cancer was reported in three cases. Histological examination of these cases did not support continuity between the xanthogranuloma and adenocarcinoma. In the other case of XGI in the terminal ileum reported by Yoon et $\mathrm{al},{ }^{2}$ preoperative endoscopy and biopsy showed ulcers with acute and chronic inflammation only. However, surgical resection was considered unavoidable in view of the radiological findings highly suggestive of appendiceal cancer. While preoperative endoscopic biopsy may not be helpful to exclude malignancy as most of the lesions are submucosal, intra-operative frozen section may be helpful to avoid unnecessary radical surgery.

\section{Conclusion}

We report a case of XGI with full-thickness involvement of the terminal ileum presenting with a tender intraperitoneal mass. This report aimed to emphasise ileal involvement of XGI, although rare, as one of the differential diagnoses of mass lesions in the small bowel mimicking malignant neoplasms.

\section{Declaration}

No conflicts of interest were declared by the authors.

\section{References}

1. Oberling C. Retroperitoneal xanthogranuloma. Am J Cancer 1935;23:477-89.

2. Yoon JS, Jeon YC, Kim TY, et al. Xanthogranulomatous inflammation in terminal ileum presenting as an appendiceal mass: case report and review of the literature. Clin Endosc 2013;46:193-6.

3. Lo CY, Lorentz TG, Poon CS. Xanthogranulomatous inflammation of the sigmoid colon: a case report. Aust N Z J Surg 1996;66:643-4.

4. Oh YH, Seong SS, Jang KS, et al. Xanthogranulomatous inflammation presenting as a submucosal mass of the sigmoid colon. Pathol Int 2005;55:440-4.

5. Anadol AZ, Gonul II, Tezel E. Xanthogranulomatous inflammation of the colon: a rare cause of cecal mass with bleeding. South Med J 2009;102:196-9.

6. Dhawan S, Jain D, Kalhan SK. Xanthogranulomatous inflammation of ascending colon with mucosal involvement: report of a first case. J Crohns Colitis 2011;5:245-8.

7. Guo G, Greenson JK. Histopathology of interval (delayed) appendectomy specimens: strong association with granulomatous and xanthogranulomatous appendicitis. Am J Surg Pathol 2003;27:1147-51.

8. Zhang L, Huang X, Li J. Xanthogranuloma of the stomach: a case report. Eur J Surg Oncol 1992;18:293-5.

9. Guarino M, Reale D, Micoli G, Tricomi P, Cristofori E. Xanthogranulomatous gastritis: association with xanthogranulomatous cholecystitis. J Clin Pathol 1993;46:88-90.

10. Lespi PJ. Gastric xanthogranuloma (inflammatory malignant fibrohistiocytoma). Case report and literature review [in Spanish]. Acta Gastroenterol Latinoam 1998;28:309-10.

11. Lai HY, Chen JH, Chen CK, et al. Xanthogranulomatous pseudotumor of stomach induced by perforated peptic ulcer mimicking a stromal tumor. Eur Radiol 2006;16:23712.

12. Kubosawa H, Yano K, Oda K, et al. Xanthogranulomatous gastritis with pseudosarcomatous changes. Pathol Int 2007;57:291-5.

13. Kinoshita H, Yamaguchi S, Sakata Y, Arii K, Mori K, Kodama R. A rare case of xanthogranuloma of the stomach masquerading as an advanced stage tumor. World J Surg Oncol 2011;9:67.

14. Rogers S, Slater DN, Anderson JA, Parsons MA. Cutaneous xanthogranulomatous inflammation: a potential indicator of internal disease. Br J Dermatol 1992;126:290-3.

15. Chuang YF, Cheng TI, Soong TC, Tsou MH. Xanthogranulomatous appendicitis. J Formos Med Assoc 2005;104:752-4. 